\title{
Synergetic effect of functional cadmium-tellurium quantum dots conjugated with gambogic acid for HepG2 cell-labeling and proliferation inhibition
}

This article was published in the following Dove Press journal:

International Journal of Nanomedicine

27 September 2013

Number of times this article has been viewed

Peipei $\mathrm{Xu}{ }^{\prime}$

Jingyuan $\mathrm{Li}^{2}$

Lixin $\mathrm{Shi}^{3}$

Matthias Selke ${ }^{3}$

Baoan Chen ${ }^{4}$

Xuemei Wang 5

'Department of Hematology, The Affiliated Drum Tower Hospital of Nanjing University Medical School, Nanjing, People's Republic of China; ${ }^{2}$ Laboratory Animal Center, Institute of Comparative Medicine, Nantong University, Nantong, People's Republic of China; ${ }^{3}$ Department of Chemistry and Biochemistry, California State University - Los Angeles, Los Angeles, CA, USA; ${ }^{4}$ Department of Hematology, Zhongda Hospital, Southeast University, Nanjing, People's Republic of China; ${ }^{5}$ State Key Lab of Bioelectronics (Chien-Shiung Wu Laboratory), Southeast University, Nanjing, People's Republic of China
Correspondence: Peipei Xu Department of Hematology, The Affiliated Drum Tower Hospital of Nanjing University Medical School, Nanjing 210008, People's Republic of China Tel +86 I30 72590562 Email xupeipei06I8@gmail.com
Abstract: We prepared and studied novel fluorescent nanocomposites based on gambogic acid (GA) and cadmium-tellurium (CdTe) quantum dots (CdTe QDs) modified with cysteamine for purpose of cancer cell labeling and combined treatment. The nanocomposites were denoted as GA-CdTe. Characterization results indicated that the CdTe QDs can readily bind onto cell plasma membranes and then be internalized into cancer cells for real-time labeling and tracing of human liver hepatocellular carcinoma cell line (HepG2) cells. GA-CdTe significantly enhanced drug accumulation in HepG2 cells and inhibited cancer cell proliferation. GA-CdTe nanocomposites also improved the drug action of GA molecules in HepG2 cells and induced the $\mathrm{G}_{2} / \mathrm{M}$ phase arrest of the cancer cell cycle, promoting cell apoptosis. Given the sensitive, $\mathrm{pH}-$ triggered release of GA-CdTe, the side effects of GA anticancer agents on normal cells/tissues in the blood circulation markedly decreased. Efficient drug release and accumulation in target tumor cells were also facilitated. Thus, the fluorescent GA-CdTe offered a new strategy for potential multimode cancer therapy and provided new channels for research into naturally-active compounds extracted from traditional Chinese medicinal plants.

Keywords: cadmium-tellurium quantum dots, gambogic acid, drug delivery, cell labeling, therapy

\section{Introduction}

As an important component of complementary and alternative medicine, traditional Chinese medicine (TCM) plays a key role in many disease therapies and is practiced worldwide. $^{1,2}$ One naturally active product isolated from gamboge resin taken from the Garcinia hanburyi tree is gambogic acid (GA), which has significant antitumor activity. ${ }^{3-5}$ GA can also induce the apoptosis of cancer cell by suppressing the nuclear factor- $\kappa \mathrm{B}(\mathrm{NF}-\kappa \mathrm{B})$-signaling pathway, which in turn suppresses the vascular endothelial growth factor receptor 2 (VEGFR2) signaling pathway. ${ }^{6-9}$ The content of many active components extracted from TCM is very low, and drug research and exploitation based on TCM is costly. The toxicity impact on normal cells and tissues is also one of the most important factors affecting the extensive use of GA in disease therapy. Accordingly, strategies have been proposed to reduce its cytotoxicity, such as structure modification, new different dosage forms, and drug carriers, to find new therapy targets. ${ }^{10-12}$ Meanwhile, nanomaterials have greatly stimulated research of drug delivery and therapy optimization because of their high volume-to-surface ratios, surface tailorability, and multifunctionality. ${ }^{13,14}$ The development of nanotechnology can also provide new opportunities for the investigation and exploitation of some active compounds based on TCM. 
Semiconductor nanomaterials are widely exploited because of their superoptical properties and other distinct characteristics of nanomaterials, such as a high volumeto-surface ratio. ${ }^{15}$ For biological and clinical applications, quantum dots (QDs) are widely studied for various purposes including labeling, imaging, targeted drug delivery, and photodynamic therapy. ${ }^{16-18}$ Various types of QDs have been extensively explored and utilized in cell- or animal-based evaluations of toxicity and biocompatibility in vitro or in vivo, even at the molecular level. ${ }^{19-21}$ Cadmium-tellurium (CdTe) QDs are typical semiconductor nanomaterials with good fluorescence characteristics; they have attracted considerable attention because of their unique optical properties and their potential applications in the manufacturing of chemical sensors, optical switches, display devices, and biological labels. ${ }^{22,23} \mathrm{CdTe}$ QDs can also enter the cell nucleus through nuclear pore complexes in live human macrophages and lead to human breast epithelial cancer cell (MCF-7) death. ${ }^{24}$ Thus, CdTe QDs have potential applications as stable fluorescence probes in the field of biomedicine, as well as utility for disease tracing and diagnosis ${ }^{25}$ with functional modifications, CdTe QDs may be widely studied for use in other fields, for instance, for drug delivery or as assistant reagents.

In this study, CdTe QDs were modified by cysteamine (Cys) with a positively-charged surface. These functional QDs were studied as multifunctional nanomaterials for both labeling of cancer cells and drug delivery of GA. Figure 1 illustrates the possible labeling and combined therapy processes of fluorescent GA-CdTe nanocomposites as an integrated multimodal diagnosis and anticancer therapeutic agent. These new fluorescent cationic CdTe QDs can significantly enhance the biocompatibility of CdTe QDs and facilitate the electrostatic interaction and self-assembly of positively charged Cys-CdTe QDs with negatively charged GA molecules to form novel GA-CdTe nanocomposites. The synergetic effect of these GA-CdTe nanocomposites for human liver hepatocellular carcinoma cell line (HepG2) cells was further investigated in vitro. As a good fluorescence probe and potential drug carrier, these CdTe QDs can optimize the new potential therapy method for GA by cancer cell labeling and inhibition.

\section{Experiments Materials and reagents}

GA (molecular formula, $\mathrm{C}_{38} \mathrm{H}_{44} \mathrm{O}_{8}$; Kanion Pharmaceutical Co., Ltd., Jiangsu, People's Republic of China) was dissolved in dimethyl sulfoxide (DMSO; Sigma-Aldrich, St Louis, MO, USA), stored at $-20^{\circ} \mathrm{C}$, and then diluted as needed in Roswell Park Memorial Institute medium (RPMI) 1640 medium (Life Technologies, Carlsbad, CA, USA). We purchased 3-(4,5-Dimethylthiazol-2-yl)-2,5-diphenyltetrazolium bromide (MTT) from Sigma-Aldrich. All other reagents used in this report were analytically pure.

Cys-CdTe QDs were prepared as described elsewhere. ${ }^{26}$ In a typical procedure, GA was diluted with phosphatebuffered saline (PBS) (pH 7.4), mixed into a Cys-CdTe QDs suspension, and kept in a refrigerator at $4{ }^{\circ} \mathrm{C}$ for more than 24 hours to prepare the GA-CdTe nanocomposites. These GA-CdTe nanocomposites were separated by centrifugation at 15,000 rpm for 20 minutes, and the supernatant GA was determined by high-performance liquid chromatography (HPLC) as shown in our previous report. ${ }^{27}$ Particle size distribution was measured with a Zetasizer NanoZS size analyzer (ZS90; Malvern Instruments, Malvern, UK) using Dynamic Light Scattering of GA-CdTe nanocomposites. The diameter of the Cys-CdTe QDs was about $3 \mathrm{~nm}$, and

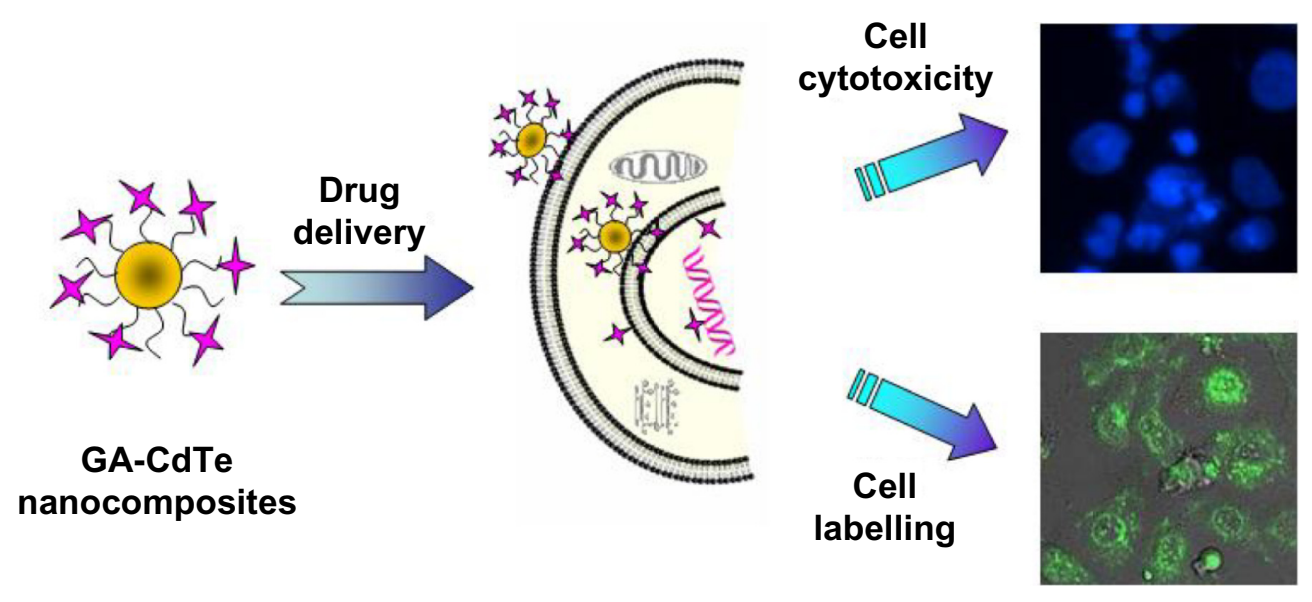

Figure I Labeling and combined therapy of the fluorescent GA-CdTe nanocomposites for HepG2 cancer cells.

Abbreviations: GA-CdTe, nanocomposites based on gambogic acid (GA) and cadmium-tellurium (CdTe) quantum dots (CdTe QDs); HepG2, human liver hepatocellular carcinoma cell line. 
the hydrodynamic size of the GA-CdTe nanocomposites was $5 \mathrm{~nm}$. The loading efficiency and encapsulation efficiency of GA loaded on Cys-CdTe QDs were $15.11 \% \pm 3.4 \%$ and $70.22 \% \pm 5.3 \%$, respectively.

\section{Cell culture}

Human embryonic lung fibroblast (HELF) (Shanghai Institute of Cells, Chinese Academy of Sciences, Shanghai, People's Republic of China) cells and HepG2 cells (Shanghai Institute of Cells, Chinese Academy of Sciences) were maintained in Dulbecco's Modified Eagle's Medium (DMEM) (high glucose; Life Technologies) supplemented with $10 \%$ fetal calf serum (Sigma-Aldrich), $100 \mathrm{U} / \mathrm{mL}$ penicillin (Sigma-Aldrich), and $100 \mu \mathrm{g} / \mathrm{mL}$ streptomycin (Sigma-Aldrich) at $37^{\circ} \mathrm{C}$ with $5 \% \mathrm{CO}_{2}$ in a $95 \%$ humidified atmosphere.

\section{MTT assay for the proliferation of HepG2 cells in the presence of Cys-CdTe QDs, GA molecule, and GA-CdTe nanocomposites}

HELF and HepG2 cells $\left(5 \times 10^{3} / \mathrm{mL}\right)$ in the log phase were trypsinized and seeded onto 96-well plates. After 24 hours incubation, the cells were rinsed in RPMI 1640 medium and incubated with different concentrations of CdTe QDs $(6.25,12.5,25,50,100$, and $200 \mathrm{nM})$ for 48 hours. The MTT solutions were added after treatment, and the cells were incubated for another 4 hours. DMSO was added to the solubilize formazan crystal, and $\mathrm{OD}_{570}$ (optical density at $570 \mathrm{~nm}$ ) was recorded. Every experiment was repeated at least three times.

The GA solutions and GA-CdTe nanocomposites were diluted with PBS ( $\mathrm{pH} 7.4$ ) and cultured with HepG2 cells having different concentrations of GA or nanocomposites. The procedure for the cell cultures and treatment of GA and GA-CdTe nanocomposites was similar to that of the MTT assay above.

\section{Labeling and imaging of HepG2 cells cultured with CdTe QDs and GA-CdTe nanocomposites}

HepG2 cells $\left(5 \times 10^{4} / \mathrm{mL}\right)$ were cultured with Cys-CdTe QDs $(10 \mathrm{nM})$ or GA-CdTe nanocomposites for about 12 hours and collected. The pellets were resuspended with PBS and centrifuged by the same procedure, and the supernatant solutions were discarded. The pellets were resuspended with PBS to eliminate the effect of the medium on fluorescence detection. The cell suspension was detected on a Leica TCS SP2 (Leica Microsystems, Wetzlar, Germany). The freshly prepared cell culture was dropped on a cleaned glass plate immediately before the measurement. The excitation wavelength of the fluorescence was $480 \mathrm{~nm}$ and the emission wavelength of the QD was $565 \mathrm{~nm}$. All the optical measurements were carried out at room temperature $\left(20^{\circ} \mathrm{C} \pm 2{ }^{\circ} \mathrm{C}\right)$.

\section{Cell morphological assessment with DAPI staining}

Cancer cells were inoculated onto glass coverslips in a sixwell plate. After 24 hours, cells were treated with different drug systems containing $0.5 \mu \mathrm{g} / \mathrm{mL}$ GA, and $0.5 \mu \mathrm{g} / \mathrm{mL}$ GA conjugated with $5 \mathrm{nM} \mathrm{CdTe}$ QDs at $37^{\circ} \mathrm{C}$ for 24 hours. Afterwards, the HepG2 cells were washed with PBS twice and fixed with methanol for 15 minutes. The fixed cells were then stained with 4',6-diamidino-2-phenylindole (DAPI) fluorochrome dye (Santa Cruz Biotechnologies, Inc., Santa Cruz, CA, USA) and observed under a fluorescent microscope (IX51; Olympus Corporation, Tokyo, Japan) with a peak excitation wavelength of $340 \mathrm{~nm}$ and an emission wavelength of $488 \mathrm{~nm}$.

\section{Apoptosis assay of GA and GA-CdTe nanocomposites for HepG2 cells}

HepG2 cells were treated with GA or GA-CdTe nanocomposites, collected by centrifugation at $1,000 \mathrm{rpm}$ for $5 \mathrm{~min}$ utes, and then washed with PBS twice. The pellets were resuspended with PBS, centrifuged, and the supernatant solutions were discarded. Subsequently, $500 \mu \mathrm{L}$ of binding buffer was added, mixed with $5 \mu \mathrm{L}$ of annexin V-FITC solution (Nanjing Keygen Biotech Co., Ltd., Nanjing, People's Republic of China), and then added with $5 \mu \mathrm{L}$ of propidium iodide solution. All the volumes of reagents solutions and empirical procedure were followed by the reagent instruction, so there is no concentrations for the reagents. The resulting mixture was kept at room temperature in the dark for 10 minutes. Flow cytometry analyses were performed using a FACS Vantage flow cytometer (Becton Dickinson, Franklin Lakes, NJ, USA), in which the excitation wavelength was $488 \mathrm{~nm}$ and the emission wavelength was $530 \mathrm{~nm}$.

\section{Cell cycle analysis of GA and GA-CdTe nanocomposites for HepG2 cells}

HepG2 cells were treated with the same drug systems previously mentioned, collected by centrifugation at 1,000 rpm for 5 minutes, washed with PBS twice, and then stained with $25 \mu \mathrm{g} / \mathrm{mL}$ propidium iodide solutions. Cell cycle analysis was performed using a Cycletest plus DNA reagent kit (Nanjing 
Keygen Biotech Co., Ltd.). Flow cytometry analysis was performed as previously described.

\section{Results and discussion Cytotoxicity of CdTe QDs for HepG2 and HELF cells}

The cytotoxicity of CdTe QDs to HepG2 and HELF cells was studied; the results are shown in Figure 2. The cytotoxicity of the CdTe QDs for HepG2 and HELF cells was found to be dose dependent. Low cytotoxicity with more than $92 \%$ survival rate was observed when the QD concentration was less than $12.5 \mathrm{nM}$, but cytotoxicity significantly increased when the QD concentration was more than $25.0 \mathrm{nM}$. The half maximal inhibitory concentration $\left(\mathrm{IC}_{50}\right)$ of the QDs for HepG2 cells was about $58.9 \mathrm{nM}$. Findings also indicated that the $\mathrm{IC}_{50}$ of CdTe QDs for HELF cells was $58.1 \mathrm{nM}^{27}$ Compared with the QD cytotoxicity of other cancer cells such as K562 and K562/A02, the CdTe QDs had little effect on both HELF and HepG2 cells. The concentration of CdTe QDs can be controlled and maintained using a suitable concentration for possible biological and medical application. Accordingly, we chose $10.0 \mathrm{nM}$ CdTe QDs for subsequent studies.

\section{Cytotoxicity of GA and GA-CdTe nanocomposites to HepG2 cells}

As active compounds extracted from natural plants, GA exhibits anticancer activity and induces the apoptosis of several kinds of cancer cells. In this work, the cytotoxicity of GA to HepG2 cells was further studied and the results are shown in Figure 3. Inhibition of the procreation of

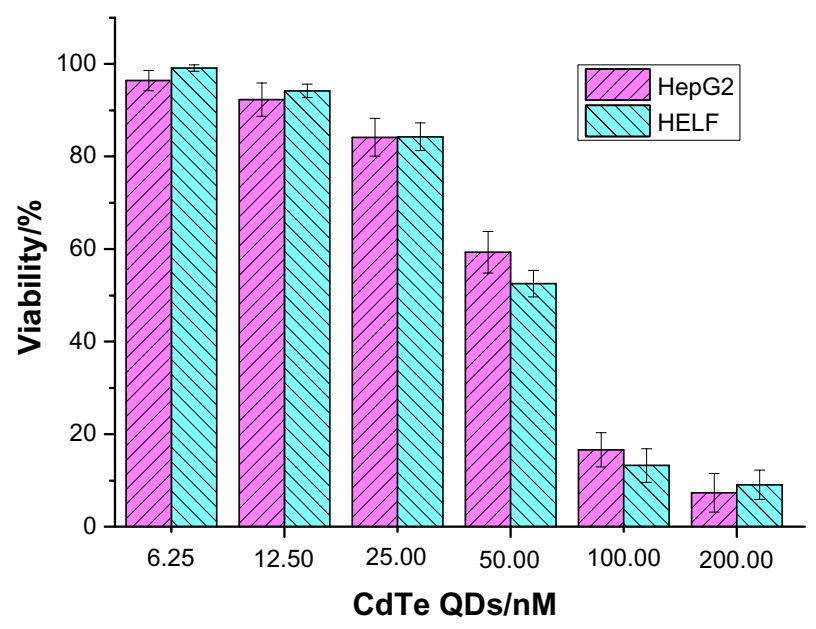

Figure 2 The cytotoxicity of CdTe QDs for HepG2 and HELF cells in vitro $(P>0.05)$. Abbreviations: CdTe QDs, cadmium-tellurium quantum dots; HepG2, human liver hepatocellular carcinoma cell line; HELF, human embryonic lung fibroblast cells; GA-CdTe, nanocomposites based on gambogic acid (GA) CdTe QDs.

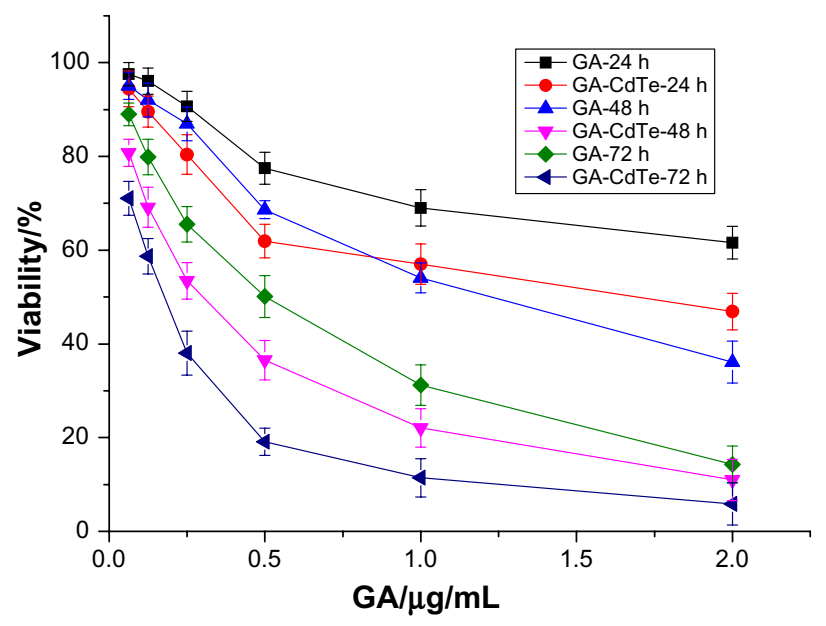

Figure 3 The cytotoxicity of GA and GA-CdTe nanocomposites for HepG2 cells. Abbreviations: GA, gambogic acid; GA-CdTe, nanocomposites based on gambogic acid (GA) and cadmium-tellurium (CdTe) quantum dots (CdTe QDs); HepG2, human liver hepatocellular carcinoma cell line.

HepG2 cells increased with increased GA concentration and culture time. The cytotoxicity of GA to HepG2 cells was dose-dependent and time-dependent. The $\mathrm{IC}_{50}$ of GA was about $2.47,1.19$, and $0.45 \mu \mathrm{g} / \mathrm{mL}$ after the HepG2 cells were treated with GA for 24,48 , and 72 hours, respectively. Thus, the naturally-active molecular GA was also sensitive to HepG2 cells.

The GA-CdTe nanocomposites were introduced into the cells to investigate the cooperative effect of cytotoxicity. As shown in Figure 3, cytotoxicity was markedly enhanced and exhibited dose and time dependence. The inhibition rate significantly increased with increased culture time compared with other active natural compounds. In the presence of CdTe QDs, the $\mathrm{IC}_{50}$ of GA was 1.35, 0.28, and $0.15 \mu \mathrm{g} / \mathrm{mL}$ after 24,48 , and 78 hours, respectively. The $\mathrm{IC}_{50}$ volume of GA under different drug systems was compared and the results are shown in Figure 4. The $\mathrm{IC}_{50}$ of GA for HepG2 cells significantly decreased in the presence of CdTe QDs after the same culture time. The $\mathrm{IC}_{50}$ volume of GA for 48 hours in the GA-CdTe nanocomposites system was even less than that for 72 hours in the negative control with only GA. Thus, the time was especially shortened to obtain the same cytotoxicity results. Compared with the negative control treated with GA, cell viability significantly decreased in the nanocomposite system. This synergetic effect also exhibited a slight increase after culture. Thus, we can presume that CdTe QDs can act as good drug carriers. Similar to our previous report, the cytotoxicity of GA and GA-CdTe nanocomposites for HELF cells was much less than that for leukemia cancer cells, indicating that GA was much safer for normal human cells. 


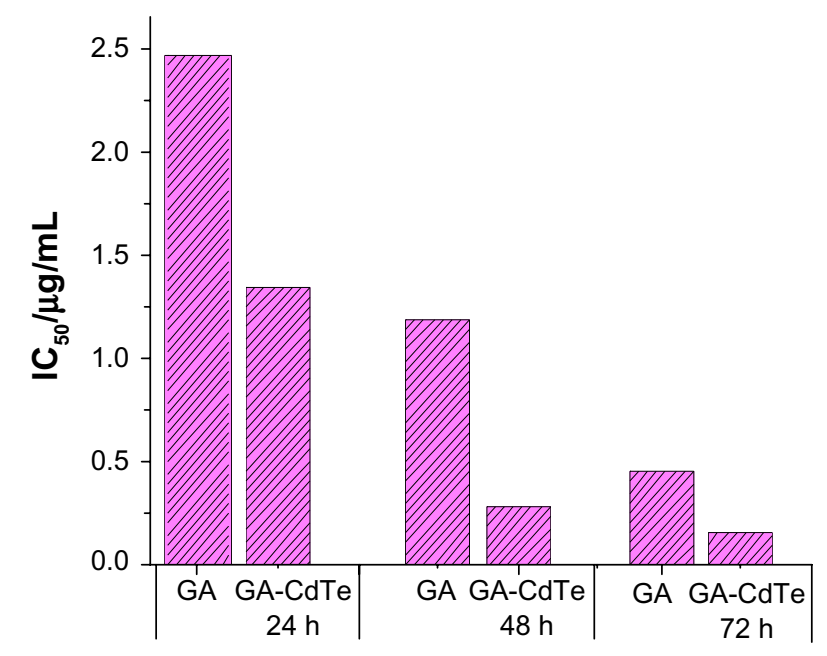

Figure $4 \mathrm{IC}_{50}$ comparison of GA in the absence and presence of CdTe QDs for HepG2 cells following the cultured time.

Abbreviations: $\mathrm{IC}_{50}$, half maximal inhibitory concentration; GA, gambogic acid; CdTe QDs, cadmium-tellurium quantum dots; HepG2, human liver hepatocellular carcinoma cell line; $h$, hours.

\section{Fluorescence imaging and cellular labeling based on CdTe QDs or GA-CdTe nanocomposites for HepG2 cells}

QDs have better fluorescence compared with traditional organic dye agents and are widely studied as a fluorescence probe in the biomedical field. In this study, Cys-modified CdTe QDs were also investigated for cancer cell labeling and imaging. Figure 5A shows no fluorescence for HepG2 cells in the negative control systems treated with GA, and HepG2 cells cannot be easily detected. After incubating the cancer cells with CdTe QDs, HepG2 cells were easily detected by laser confocal fluorescence microscopy, and the results are shown in Figure 5B. After the HepG2 cells were cultured with GA-CdTe nanocomposites in the positive system, the cancer cells could be observed by the generated fluorescence of the CdTe QDs. No apparent difference was observed in the fluorescence intensity between the negative and positive systems, as shown in Figure 5B and C. Given that no fluorescence was found for GA molecules and the cell, ${ }^{27}$ intracellular fluorescence was generated only by the CdTe QDs, and the nanocomposites did not affect the fluorescence intensity of the CdTe QDs. According to the above results, CdTe QDs and GA-CdTe nanocomposites in drug delivery can be studied as fluorescence probes for labeling and imaging HepG2 cells. These materials can also be investigated to detect and trace the changes in target cells in real-time.

\section{Analysis of cancer cells apoptosis induced by GA and GA-CdTe nanocomposites}

GA can cause the apoptosis of some cancer cells such as K562 and K562/A02 cells to create cytotoxicity. In this study, we examined amorphous changes in different cell systems treated by drugs or nanocomposites. Figure $6 \mathrm{~A}$ shows that the HepG2 cells in the blank group were stained with weak fluorescence using the equally distributed chromatin in the nucleolus, indicating the healthy condition of the cells. After treatment with GA for 24 hours, some HepG2 cells were detected with typical cytomorphological features of apoptosis, such as cell shrinkage, chromatin condensation, and the presence of apoptotic bodies, as shown in Figure 6B. After incubation with $0.5 \mu \mathrm{g} / \mathrm{mL}$ GA-CdTe nanocomposites for 24 hours, more HepG2 cells emitted bright fluorescence and displayed typical phenomena of apoptosis, including chromatin condensation, nucleolus pyknosis, and nuclear fragmentation (Figure 6C).

Flow cytometry was then used to quantitatively investigate the apoptosis of HepG2 cells. After 24 hours of culture, the total apoptosis rate was $8.9 \%$ in the blank experiments of HepG2 cells, as shown in Figure 7B. After the cells were
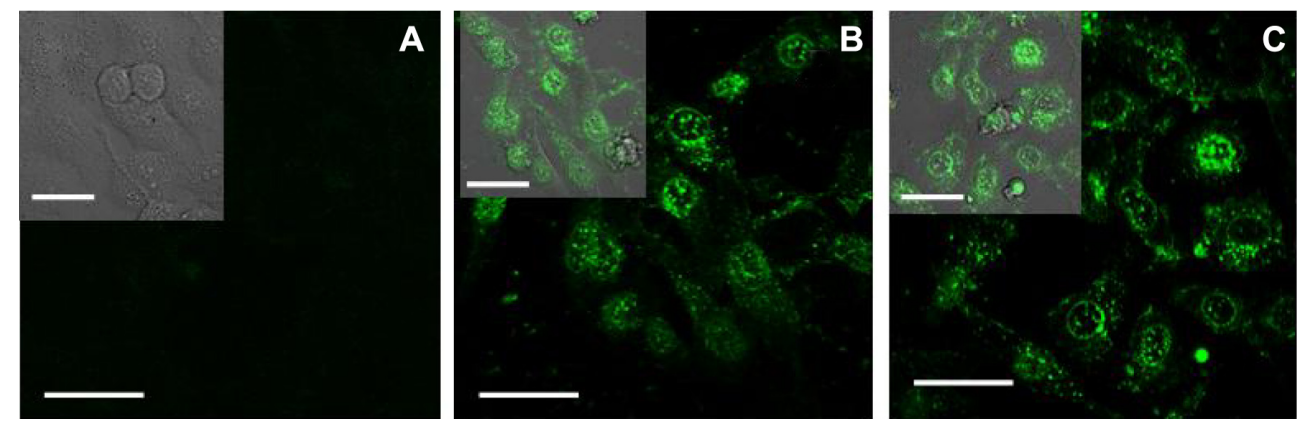

Figure 5 Confocal fluorescence microscopy images of HepG2 cells treated with CdTe QDs or GA-CdTe nanocomposites.

Notes: (A) HepG2 treated with GA; (B) HepG2 treated with CdTe QDs; (C) HepG2 treated with GA-CdTe nanocomposites. Scale bar: $20 \mu$ m.

Abbreviations: HepG2, human liver hepatocellular carcinoma cell line; GA, gambogic acid; CdTe QDs, cadmium-tellurium quantum dots; GA-CdTe, nanocomposites based on GA and CdTe QDs. 

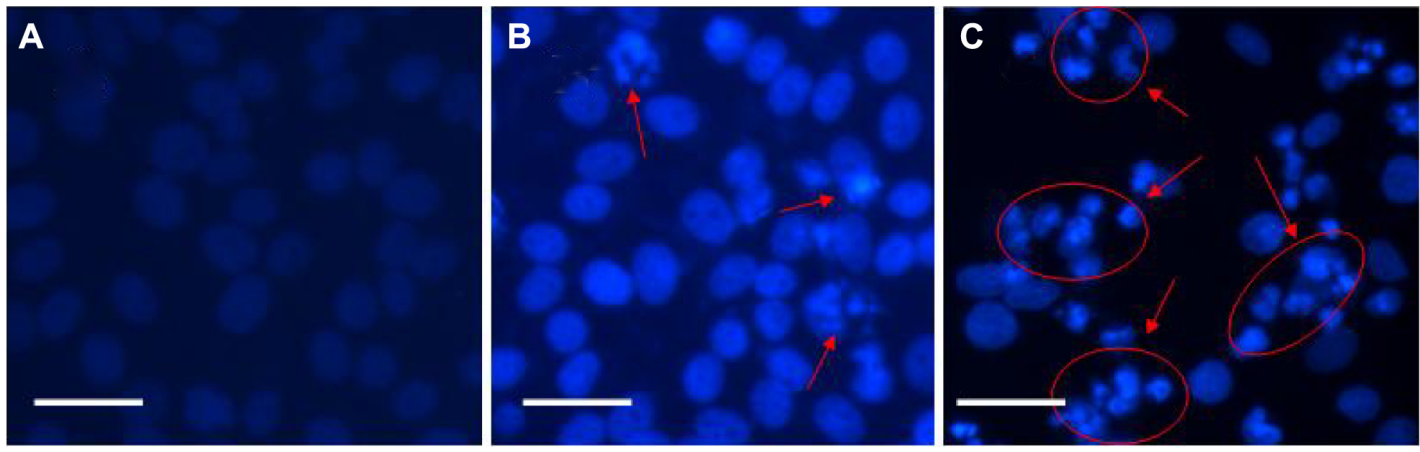

Figure 6 Optical microscopy images of cancer cells.

Notes: (A) HepG2 cells; (B) HepG2 treated with GA; (C) HepG2 treated with GA-CdTe nanocomposites. Scale bar: $20 \mu \mathrm{m}$.

Abbreviations: HepG2, human liver hepatocellular carcinoma cell line; GA, gambogic acid; CdTe QDs, cadmium-tellurium quantum dots; GA-CdTe, nanocomposites based on GA and CdTe QDs.

cultured with GA $(0.5 \mu \mathrm{g} / \mathrm{mL})$, the early apoptosis and late apoptosis rate increased to $17.6 \%$ and $5.1 \%$, respectively (Figure 7C), and no significant difference was observed compared with the blank experiments. After the GA-CdTe nanocomposites were introduced into HepG2 cells, the apoptosis rate increased to $49.1 \%$, with the early apoptosis rate increasing to $24.0 \%$ and late apoptosis rate increasing to 25.1\%, as shown in Figure 7D. Figure 7A shows a significant increase in cell apoptosis rate compared with the blank and negative experiments of the GA-cultured cells.

Based on all these observations, we presume that CdTe QDs can act as a drug carrier to facilitate drug GA delivery and transport them into HepG2 cells. The GA-CdTe nanocomposites had an apparent synergistic effect on the drug uptake of GA in HepG2 cells, leading to the apparent apoptosis of targeted cancer cells. The GA-CdTe nanocomposites can strengthen the drug action of GA for HepG2 cells by enhancing drug accumulation in cancer cells. CdTe QDs may have an important role as a new strategy for the effective treatment of targeted cancers.

\section{Effect of GA and GA-CdTe nanocomposites on cells cycle by flow cytometry analysis}

The following cell cycle study was conducted to investigate the relative mechanism of the above systems. According to a previous
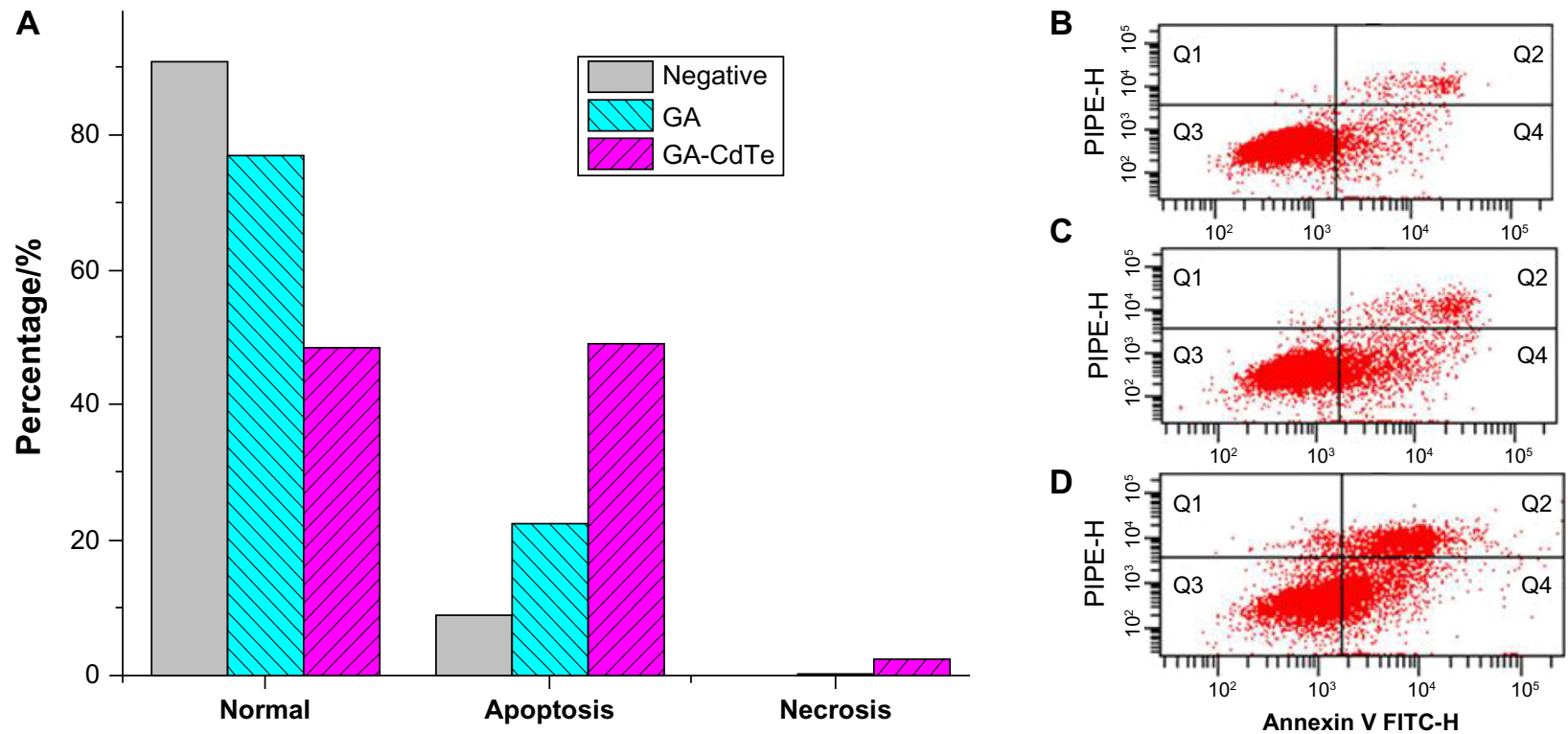

Figure 7 Effect of GA and drug-nanocomposites induced apoptosis in HepG2 cells for 24 hours.

Notes: (A) The apoptosis analysis of HepG2 cells in which (B) HepG2 cells, (C) HepG2 incubated with $0.5 \mu \mathrm{g} / \mathrm{mL}$ GA, and (D) HepG2 incubated with GA-CdTe QDs nanocomposites. Q3: healthy; Q4: apoptosis; Q2: late apoptosis; Q1: cell debris.

Abbreviations: HepG2, human liver hepatocellular carcinoma cell line; GA, gambogic acid; CdTe QDs, cadmium-tellurium quantum dots; GA-CdTe, nanocomposites based on GA and CdTe QDs. 
A

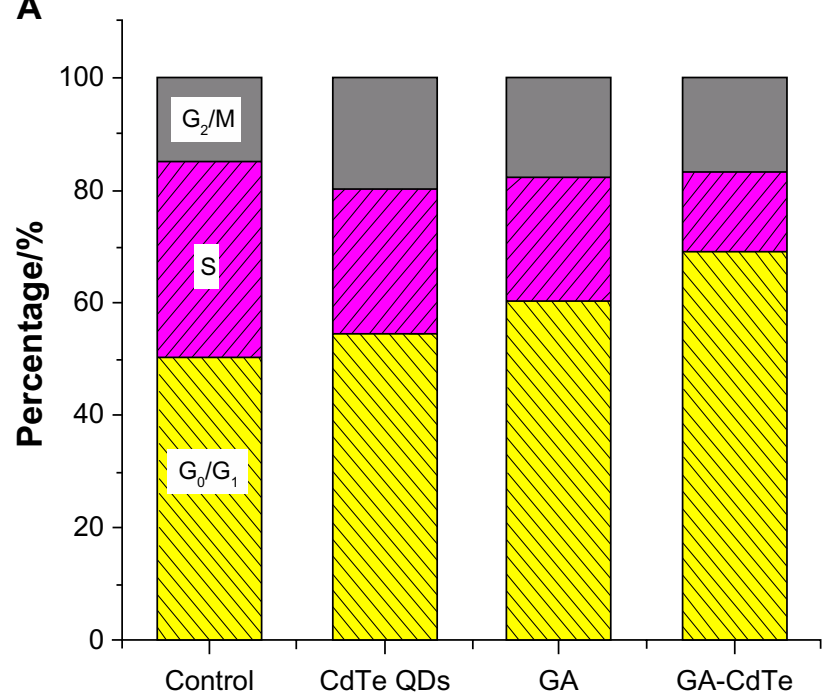

B

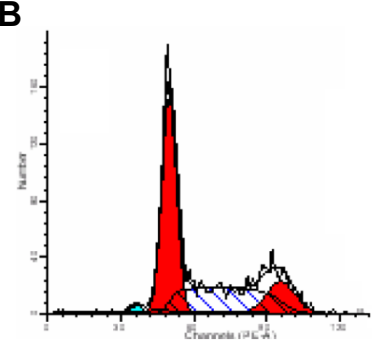

D

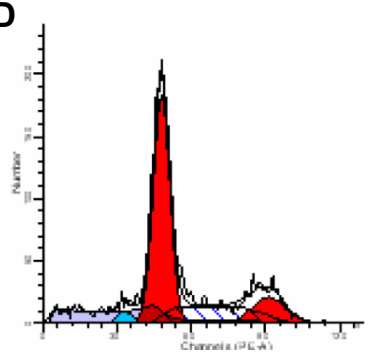

C

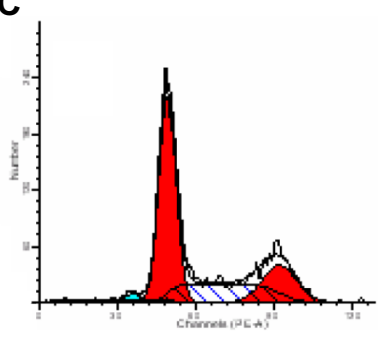

E

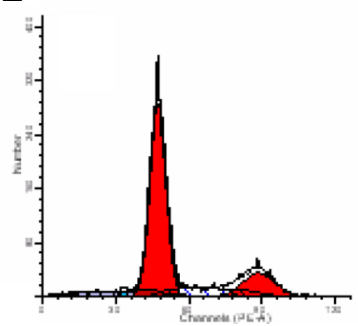

Figure 8 Effect of GA, CdTe QDs and GA-CdTe nanocomposites for HepG2 cells' cycle.

Notes: (A) Effect of GA, CdTe QDs and GA-CdTe nanocomposites for HepG2 cells' cycle; (B) HepG2 cells; (C) HepG2 incubated with 10 nM CdTe QDs; (D) HepG2 incubated with $0.5 \mu \mathrm{g} / \mathrm{mL} \mathrm{GA}$; (E) HepG2 incubated with GA-CdTe nanocomposites for 24 hours.

Abbreviations: GA, gambogic acid; CdTe QDs, cadmium-tellurium quantum dots; GA-CdTe, nanocomposites based on GA and CdTe QDs; HepG2, human liver hepatocellular carcinoma cell line.

report, GA can induce $\mathrm{G}_{0} / \mathrm{G}_{1}$ arrest and $\mathrm{K} 562$ apoptosis. ${ }^{27}$ Figure $8 \mathrm{~B}$ shows that the ratio of the $\mathrm{G}_{0} / \mathrm{G}_{1}$ phase was about $50.43 \%$, whereas the ratio of the $\mathrm{S}$ phase was about $34.69 \%$, in the blank experiments of HepG2 cells. These results indicated that CdTe QDs had a small effect on HepG2 cells cycle, with $54.38 \% \mathrm{G}_{0} / \mathrm{G}_{1}$ phase and $26.15 \% \mathrm{~S}$ phase, as shown in Figure $8 \mathrm{C}$. After the cells were cultured with GA for 24 hours, the ratio of the $\mathrm{G}_{0} / \mathrm{G}_{1}$ phase increased to $60.29 \%$, whereas that of the $\mathrm{S}$ phase decreased to $22.25 \%$, as shown in Figure $8 \mathrm{D}$. When the HepG2 cells were cultured with GA-CdTe nanocomposites for 24 hours, the $\mathrm{G}_{0} / \mathrm{G}_{1}$ phase increased to $68.92 \%$ and the $\mathrm{S}$ phase decreased to $14.22 \%$, as shown in Figure 8E. Figure 8A shows the comparison among the effect of GA,CdTe ODs and GA-CdTe nanocomposites for HepG2 cells' cycle. An obvious arrest by about $20.30 \%$ for the $\mathrm{G}_{0} / \mathrm{G}_{1}$ phase compared with the GA-treated system was observed. Thus, the GA-CdTe nanocomposites can enhance the cytotoxicity of GA to inhibit the growth of HepG2 cells by perturbation of the cycle signaling network (through the $\mathrm{G}_{0} / \mathrm{G}_{1}$ phase).

\section{Conclusion}

Novel fluorescent GA-CdTe nanocomposites based on GA and CdTe QDs were studied for HepG2 cancer cell imaging and combined treatment. Compared with normal cell membranes, which are characterized by zwitterionic phospholipids as red blood cells, many cancer cell membranes have more anionic phospholipids in their outer leaflet, as well as O-glycosylated mucin. Thus, the electrostatic interaction of the CdTe QDs with the positively and negatively charged cancer cell surface and membrane components contributed to the selectivity toward cancer cells. CdTe QDs can readily bind to HepG2 cells plasma membranes and then be internalized into the cells for real-time labeling and imaging of HepG2 cells. The GACdTe nanocomposites enhanced the drug accumulation on HepG2 cells and significantly inhibited cancer cell proliferation. The GA-CdTe nanocomposites improved the drug action of the GA molecular to the HepG2 cells and induced $\mathrm{G}_{0} / \mathrm{G}_{1}$ phase arrest of the cancer cell cycle to promote cell apoptosis. Moreover, the nanocomposites with sensitive $\mathrm{pH}$-triggered release markedly reduced the side effects of the anticancer agent GA to the normal cells/tissues in the blood circulation, and facilitated efficient drug release and accumulation in target tumor cells. Thus, fluorescent GA-CdTe nanocomposites can offer a new strategy for potential multimode cancer therapy and provide a new channel for research into the natural active compounds extracted from TCM plants.

\section{Acknowledgments}

This work was supported by National Basic Research Program of China (No 2010CB732404), National Natural Science Foundation of China $(81170492,21175020)$. M Selke and LX Shi acknowledge support from the United States NSF_CREST program, NSF-HED0932421.

\section{Disclosure}

The authors report no conflicts of interest in this work. 


\section{References}

1. Ahmed S, Anuntiyo J, Malemud CJ, Haqqi TM. Biological basis for the use of botanicals in osteoarthritis and rheumatoid arthritis: a review. Evid Based Complement Alternat Med. 2005;2(3):301-308.

2. Yang H, Chen D, Cui QC, Yuan X, Dou QP. Celastrol, a triterpene extracted from the Chinese "Thunder of God Vine," is a potent proteasome inhibitor and suppresses human prostate cancer growth in nude mice. Cancer Res. 2006;66(9):4578-4765.

3. Liu WY, Feng F, You QD, Zhang ZX. Improvement in the measurement of active ingredient content in injectable liquid of gambogic acid. Chin Trad Patent Med. 2004;26:8-9.

4. Gu H, Wang X, Rao S, et al. Gambogic acid mediates apoptosis as a p53 inducer through down-regulation of $\mathrm{mdm} 2$ in wild-type p53expressing cancer cells. Mol Cancer Ther. 2008;7(10):3298-3305.

5. Gu H, You Q, Liu W, et al. Gambogic acid induced tumor cell apoptosis by $\mathrm{T}$ lymphocyte activation in $\mathrm{H} 22$ transplanted mice. Int Immunopharmacol. 2008;8(11):1493-1502.

6. Gu H, Rao S, Zhao J, et al. Gambogic acid reduced bcl-2 expression via p53 in human breast MCF-7 cancer cells. J Cancer Res Clin Oncol. 2009;135(12):1777-1782.

7. Kasibhatla S, Jessen KA, Maliartchouk S, et al. A role for transferrin receptor in triggering apoptosis when targeted with gambogic acid. Proc Natl Acad Sci U S A. 2005;102(34):12095-12100.

8. Zhai D, Jin C, Shiau CW, Kitada S, Satterthwait AC, Reed JC. Gambogic acid is an antagonist of antiapoptotic Bcl-2 family proteins. Mol Cancer Ther. 2008;7(6):1639-1646.

9. Yi T, Yi Z, Cho SG, et al. Gambogic acid inhibits angiogenesis and prostate tumor growth by suppressing vascular endothelial growthfactor receptor 2 signaling. Cancer Res. 2008;68(6):1843-1850.

10. Delehanty JB, Boeneman K, Bradburne CE, Robertson K, Medintz IL. Quantum dots: a powerful, tool for understanding the intricacies of nanoparticle-mediated drug delivery. Expert Opin Drug Deliv. 2009;6(10):1091-1112.

11. Juzenas P, Chen W, Sun YP, et al. Quantum dots and nanoparticles for photodynamic and radiation therapies of cancer. Adv. Drug Deliv. Rev. 2008;60(15):1600-1614.

12. Efferth T, Davey M, Olbrich A, Rücker G, Gebhart E, Davey R. Activity of drugs from traditional chinese medicine toward sensitive and MDR1or MRP1-overexpressing multidrug-resistant human CCRF-CEM leukemia cells. Blood Cells Mol Dis. 2002;28(2):160-168.

13. Hong S, Leroueil PR, Janus EK, et al. Interaction of polycationic polymers with supported lipid bilayers and cells: nanoscale hole formation and enhanced membrane permeability. Bioconjugate Chem. 2006;17(3):728-734.
14. Park H, Lee S, Chen L, et al. SERS Imaging of HER2-overexpressed MCF7 cells using antibody-conjugated gold nanorods. Phys Chem Chem Phys. 2009;11(34):7444-7449.

15. Katz E, Willner I. Integrated nanoparticle-biomolecule hybrid systems: synthesis, properties, and applications. Angew Chem Int Ed. 2004;43(45):6042-6108.

16. Wang C, Li Y, Bai J, Yang Q, Song Y, Zhang C. Characterization and photoluminescence studies of CdTe nanoparticles before and after transfer from liquid phase to polystyrene. Bull Mater Sci Vol. 2009;32(5):487-491.

17. Chugh A, Eudes F, Shim YS. Cell-penetrating peptides: nanocarrier for macromolecule delivery in living cells. IUBMB Life. 2010;62(3): 183-193.

18. Medintz IL, Uyeda HT, Goldman ER, Mattoussi H. Quantum dot bioconjugates for imaging, labelling and sensing. Nature Mater. 2005;4(6):435-446.

19. Kirchner C, Liedl T, Kudera S, et al. Cytotoxicity of colloidal CdSe and CdSe/ZnS nanoparticles. Nano Lett. 2005;5(2):331-338.

20. Lovrić J, Cho SJ, Winnik FM, Maysinger D. Unmodified cadmium telluride quantum dots induce reactive oxygen species formation leading to multiple organelle damage and cell death. Chem Biol. 2005;12(11): $1227-1234$

21. Zhang T, Stilwell JL, Gerion D, et al. Cellular effect of high doses of silica-coated quantum dot profiled with high throughput gene expression analysis and high content cellomics measurements. Nano Lett. 2006;6(4):800-808.

22. Li J, Hong X, Liu Y, et al. Highly Photoluminescent CdTe/Poly(Nisopropylacrylamide) Temperature-Sensitive Gels. Adv Mater. 2005; 17(2):163-166.

23. Poznyak SK, Osipovich NP, Shavel A, et al. Size-dependent electrochemical behavior of thiol-aapped CdTe nanocrystals in aqueous solution. J Phys Chem B. 2005;109(3):1094-1100.

24. Choi AO, Brown SE, Szyf M, Maysinger D. Quantum dot-induced epigenetic and genotoxic changes in human breast cancer cells. $J$ Mol Med. 2008;86(3):291-302.

25. Wu C, Shi L, Li Q, et al. Probing the dynamic effect of Cys-CdTe quantum dots toward cancer cells in vitro. Chem Res Toxicol. 2010;23(1):82-88.

26. Gaponik N, Talapin DV, Rogach AL. Thiol-capping of CdTe nanocrystals: an alternative to organometallic synthetic routes. J Phys Chem B. 2002;106(29):7177-7185.

27. Li J, Wu C, Xu P, et al. Multifunctional effects of Cys-CdTe QDs conjugated with gambogic acid for cancer cell tracing and inhibition. $R S C$ Adv. 2013;3(18):6518-6525.
International Journal of Nanomedicine

\section{Publish your work in this journal}

The International Journal of Nanomedicine is an international, peerreviewed journal focusing on the application of nanotechnology in diagnostics, therapeutics, and drug delivery systems throughout the biomedical field. This journal is indexed on PubMed Central, MedLine, CAS, SciSearch $\AA$, Current Contents $\AA /$ Clinical Medicine,

\section{Dovepress}

Journal Citation Reports/Science Edition, EMBase, Scopus and the Elsevier Bibliographic databases. The manuscript management system is completely online and includes a very quick and fair peer-review system, which is all easy to use. Visit http://www.dovepress.com/ testimonials.php to read real quotes from published authors. 